Article

\title{
Seasonal Filarial Infections and Their Black Fly Vectors in Chiang Mai Province, Northern Thailand
}

\author{
Kittipat Aupalee ${ }^{1}$, Atiporn Saeung ${ }^{2, *} \mathbb{D}$, Wichai Srisuka ${ }^{3}$, Masako Fukuda ${ }^{4}$, Adrian Streit ${ }^{5}$ \\ and Hiroyuki Takaoka ${ }^{6}$ \\ 1 Graduate Doctoral Degree Program in Parasitology, Faculty of Medicine, Chiang Mai University, \\ Chiang Mai 50200, Thailand; kittipat.aupalee@gmail.com \\ 2 Department of Parasitology, Faculty of Medicine, Chiang Mai University, Chiang Mai 50200, Thailand \\ 3 Entomology Section, Queen Sirikit Botanic Garden, P.O. Box 7, Chiang Mai 50180, Thailand; wsrisuka@gmail.com \\ 4 Institute for Research Promotion, Oita University, Idaigaoka 1-1, Hasama, Yufu City, Oita 879-5593, Japan; \\ mfukuda@oita-u.ac.jp \\ 5 Department of Integrative Evolutionary Biology, Max Planck Institute for Developmental Biology, Tübingen, \\ 72076 Baden-Württemberg, Germany; adrian.streit@tuebingen.mpg.de \\ 6 Tropical Infectious Diseases Research and Education Centre (TIDREC), University of Malaya, \\ Kuala Lumpur 50603, Malaysia; takaoka@oita-u.ac.jp \\ * Correspondence: atiporn.s@cmu.ac.th; Tel.: +66-53-945342
}

Received: 25 May 2020; Accepted: 23 June 2020; Published: 25 June 2020

check for updates

\begin{abstract}
The transmission of zoonotic filarial parasites by black flies has so far been reported in the Chiang Mai and Tak provinces, Thailand, and the bites of these infected black flies can cause a rare disease-human zoonotic onchocerciasis. However, species identification of the filarial parasites and their black fly vectors in the Chiang Mai province were previously only based on a morphotaxonomic analysis. In this study, a combined approach of morphotaxonomic and molecular analyses (mitochondrial cox1, 12S rRNA, and nuclear 18S rRNA (SSU HVR-I) genes) was used to clarify the natural filarial infections in female black flies collected by using human and swine baits from two study areas (Ban Lek and Ban Pang Dang) in the Chiang Mai province from March 2018 to January 2019. A total of 805 and 4597 adult females, belonging to seven and nine black fly taxa, were collected from Ban Lek and Ban Pang Dang, respectively. At Ban Lek, four of the 309 adult females of Simulium nigrogilvum were positive for Onchocerca species type I in the hot and rainy seasons. At Ban Pang Dang, five unknown filarial larvae (belonging to the same new species) were detected in Simulium sp. in the S. varicorne species-group and in three species in the S. asakoae species-group in all seasons, and three non-filarial larvae of three different taxa were also found in three females of the S. asakoae species-group. This study is the first to molecularly identify new filarial species and their vector black fly species in Thailand.
\end{abstract}

Keywords: Simulium; black fly; Onchocerca spp.; zoonotic onchocerciasis; cox1; 12S rRNA; 18S rRNA

\section{Introduction}

Black flies (Diptera: Simuliidae) are a group of small hematophagous insects which vector several pathogens that are responsible for animal and human diseases, particularly human onchocerciasis (river blindness) caused by the parasitic worm Onchocerca volvulus [1]. Several black fly species have also been reported to vector filarial worms of the genus Onchocerca that cause zoonotic onchocerciasis in humans. This infection is generally caused by a single immature adult worm of animal origin [2]. So far, 37 human cases of zoonotic onchocerciasis have been reported globally, including in Europe, North America, North Africa, and East Asia [3]. Recently, the 38th case, a male infected in his eye with O. jakutensis, which is a natural parasite of red deer, was reported in Poland [4]. 
Until now, a total of 35 valid Onchocerca species have been reported worldwide, including a newly described species, O. borneensis, from Malaysia [5,6]. Furthermore, Uni et al. [6] raised O. dewittei japonica to the species level (the 36th) as O. japonica, based on morphological and molecular analyses. Among these Onchocerca spp., five, namely O. gutturosa, O. cervicalis, O. jakutensis, O. lupi, and O. japonica, were identified as the causative agents of the above-mentioned zoonotic onchocerciasis [3,6].

In Thailand, two black fly species, Simulium chumpornense and Simulium asakoae s. 1., were recently reported as potential vectors of the avian blood protozoa Leucocytozoon and Trypanosoma [7-9]. Even though neither human onchocerciasis nor zoonotic onchocerciasis has been recorded in Thailand, three human-biting black fly species, namely Simulium nodosum, S. asakoae s. l., and Simulium nigrogilvum, were found to be natural vectors of three types of filarial worms in the Chiang Mai province, in the northern region of Thailand [10-12]. However, natural filarial infections in black flies in the areas of the Chiang Mai province have not been monitored and examined for over a decade. Previous studies were solely based on the morphological characters of the recovered larvae, and molecular species identification is currently missing [10-12].

In order to explore the existence of natural filarial infections in black fly species previously regarded as vectors of unknown filarial worms, we recently conducted a preliminary study in the Fang district, Chiang Mai province, northern Thailand. We determined natural filarial infections by dissecting black flies and searching for any stages of filarial larvae. The result revealed, for the first time, that two of 52 adult females of S. nigrogilvum dissected were naturally infected with third-stage larvae ( $\mathrm{L}_{3}$, infective larvae) of unknown filarial worms, which were morphologically and molecularly identified as Onchocerca sp. type I-an unnamed bovine filarial worm isolated from Simulium bidentatum in Japan [13-15]. A similar detection of $O$. sp. type I in S. nigrogilvum was recently reported in the Tak province, western Thailand, by Saeung et al. [16].

In the current study, to effectively plan public health strategies for dealing with the transmission of zoonotic filariae to humans, we attempted to gather additional information about the filarial parasites and their black fly vectors present in Thailand, as well as their geographical distribution. Therefore, we examined adult female flies to determine their natural filarial infections. Furthermore, we morphologically and molecularly analysed the infected black flies and filarial larvae recovered to elucidate their taxonomic position.

\section{Results}

\subsection{Black Fly Species Collected and Seasonal Abundance}

\subsubsection{Ban Lek (BL)}

The total numbers of female black flies collected in each season are shown in Table 1. A total of 805 females of seven black fly taxa were captured during the study period. Simulium chumpornense (39.4\%), S. nigrogilvum (38.3\%), and Simulium spp. in the S. asakoae species-group (18.4\%) were relatively abundant, whereas four other S. spp. were minor (3.9\%) (Table 1). Simulium chumpornense was only captured in the hot season (March), but then in a very high number, while S. nigrogilvum, species in the S. asakoae species-group, and species in the $S$. striatum species-group were collected throughout the year, with a peak in the hot season.

\subsubsection{Ban Pang Dang (BPD)}

The total numbers of female black flies collected in each season are shown in Table 2. Nine black fly taxa were captured throughout the year. Among the 4597 flies collected, the most abundant species was S. spp. in the S. asakoae species-group (50.7\%), followed by S. chumpornense (48.9\%) and seven other taxa $(0.4 \%)$ (Table 2). Simulium chumpornense was captured in a very high number, but only in the hot season (March), while species in the S. asakoae species-group were collected throughout the year, with a peak in the dry-cool season. 


\subsection{Natural Filarial Infections and Morphological Identification of Recovered Larvae}

\subsubsection{Ban Lek}

Natural filarial infections were only found in four females of S. nigrogilvum. Three out of the 187 S. nigrogilvum collected in the hot season, one out of the 82 collected in the rainy season, and none out of the 40 collected in the dry-cool season were naturally infected with one or two infective larvae $\left(\mathrm{L}_{3}\right)$, each in the thorax (Table 1, Figure 1A), resulting in an overall infection rate of S. nigrogilvum of $1.3 \%$. The sizes of these larvae were 1027.1-1339.5 $\mu \mathrm{m}$ long by 25.6-29.6 $\mu \mathrm{m}$ wide (Table 3). All six recovered larvae were morphologically similar to one another and were identified as belonging to the genus Onchocerca [17]. These larvae were most similar in size (width and length) and morphology to O. sp. type I $[13,16]$.

\subsubsection{Ban Pang Dang}

In total, nine female black flies (S. sp. $(n=1)$ and $S$. asakoae species-group $(n=8))$ were infected with unknown nematode larvae. Ten larvae were recovered from these infected flies and tentatively identified as filarial nematodes $(n=5)$, non-filarial nematodes $(n=3)$, and unidentified nematodes $(n=2)$, based on their morphological characters. Natural infections with filarial larvae were found over the year in two black fly species, including one in the $S$. sp. (collected in the hot season, $\mathrm{L}_{1}$ ) and three in the $S$. asakoae species-group. Of the $S$. asakoae species-group, one of 635 collected in the rainy season and two of 1175 collected in the dry-cool season were infected (Table 2). One or two infective larvae $\left(\mathrm{L}_{3}\right)$ were recovered from the thoraxes of each infected female (Figure 1B). Furthermore, three females of the $S$. asakoae species-group collected in the rainy and dry-cool seasons were also naturally infected with three non-filarial larvae. One of these larvae was morphologically identified as a mermithid nematode (Figure 1C) and the other two larvae were morphologically identified as two different, unknown non-filarial nematodes (Figure 1D,E). For two larvae recovered from flies of the S. asakoae species-group (one collected in the hot season (June: Mf) and one collected in the rainy season (November, $\left.L_{1}\right)$ ), the species status could not be evaluated due to damage, which made morphological observations difficult and prevented molecular analysis (Table 3).

Table 1. Seasonal abundance and natural filarial infections of female black flies collected at Ban Lek, Fang district, Chiang Mai province, northern Thailand, from March 2018 to January 2019.

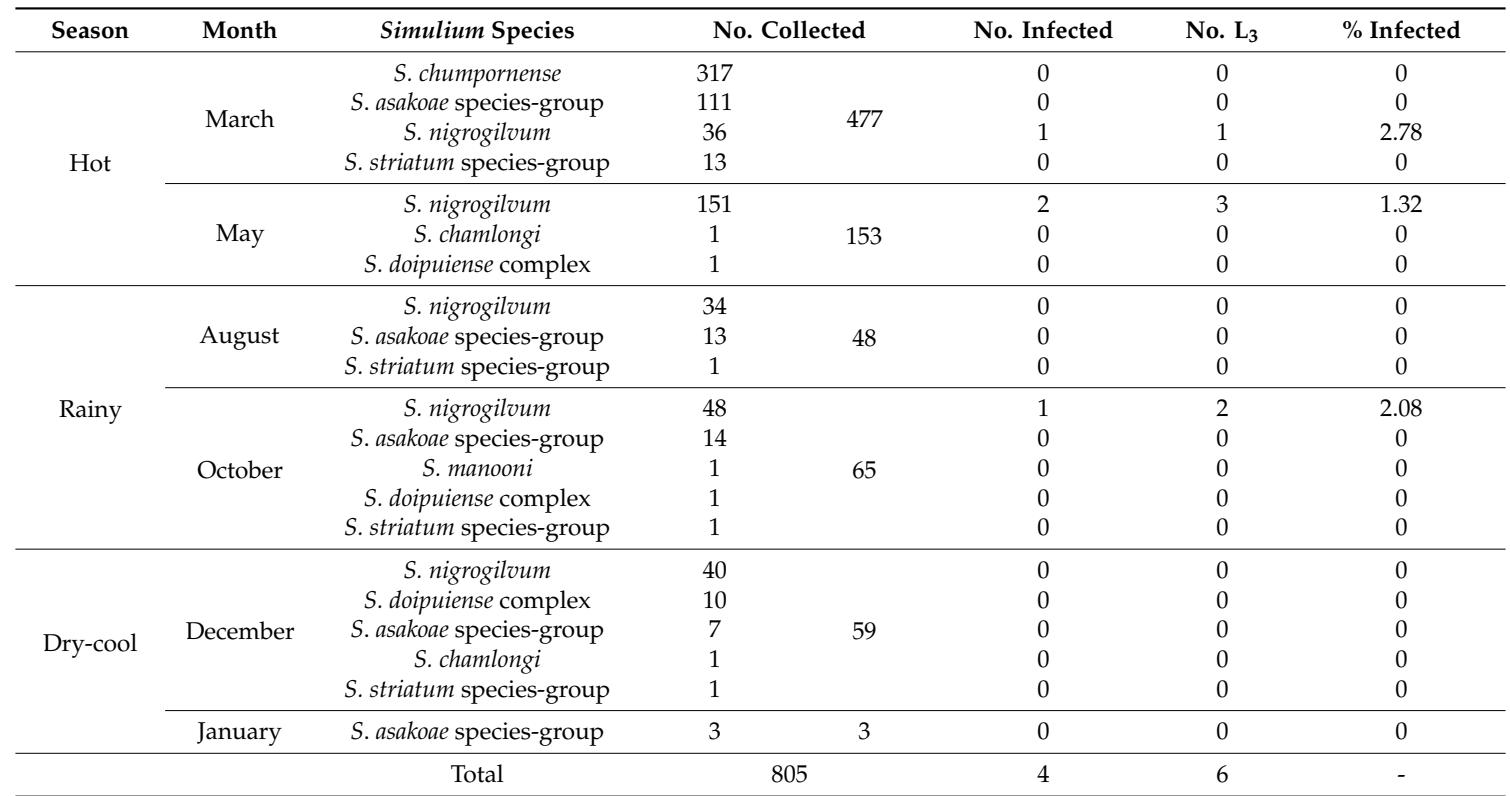

Abbreviation: $\mathrm{L}_{3}=$ third-stage larva (infective larva). 
Table 2. Seasonal abundance and natural nematode infections of female black flies collected at Ban Pang Dang, Doi Saket District, Chiang Mai province, northern Thailand, from March 2018 to January 2019.

\begin{tabular}{|c|c|c|c|c|c|c|c|c|c|}
\hline \multirow{2}{*}{ Season } & \multirow{2}{*}{ Month } & \multirow{2}{*}{ Simulium Species } & \multirow{2}{*}{\multicolumn{2}{|c|}{ No. Collected }} & \multirow{2}{*}{ No. Infected } & \multicolumn{3}{|c|}{ No. Larva } & \multirow{2}{*}{$\%$ Infected } \\
\hline & & & & & & FL & NFL & UID & \\
\hline \multirow{5}{*}{ Hot } & \multirow{4}{*}{ March } & S. chumpornense & 2249 & \multirow{4}{*}{2616} & 0 & 0 & 0 & 0 & 0 \\
\hline & & S. asakoae species-group & 363 & & 0 & 0 & 0 & 0 & 0 \\
\hline & & S. nigrogilvum & 3 & & 0 & 0 & 0 & 0 & 0 \\
\hline & & S. sp. & 1 & & 1 & $1 \mathrm{~L}_{1}$ & 0 & 0 & 100 \\
\hline & June & S. asakoae species-group & 157 & 157 & 1 & 0 & 0 & $1 \mathrm{Mf}$ & 0.64 \\
\hline \multirow{2}{*}{ Rainy* } & \multirow{2}{*}{ September } & S. asakoae species-group & 635 & \multirow{2}{*}{636} & 2 & $1 \mathrm{~L}_{3}$ & $1 \mathrm{~L}_{3}$ & 0 & 0.31 \\
\hline & & S. striatum species-group & 1 & & 0 & 0 & 0 & 0 & 0 \\
\hline \multirow{8}{*}{ Dry-cool } & November & S. asakoae species-group & 368 & 368 & 3 & $2 \mathrm{~L}_{3}$ & $1 \mathrm{~L}_{3}$ & $1 \mathrm{~L}_{1}$ & 0.82 \\
\hline & \multirow{6}{*}{ January } & S. asakoae species-group & 807 & \multirow{6}{*}{820} & 2 & $1 \mathrm{~L}_{3}$ & $1 \mathrm{~L}_{3}$ & 0 & 0.25 \\
\hline & & S. striatum species-group & 8 & & 0 & 0 & 0 & 0 & 0 \\
\hline & & S. chamlongi & 2 & & 0 & 0 & 0 & 0 & 0 \\
\hline & & S. tani & 1 & & 0 & 0 & 0 & 0 & 0 \\
\hline & & S. bullatum & 1 & & 0 & 0 & 0 & 0 & 0 \\
\hline & & S. lampangense & 1 & & 0 & 0 & 0 & 0 & 0 \\
\hline & & Total & \multicolumn{2}{|c|}{4597} & 9 & 5 & 3 & 2 & - \\
\hline
\end{tabular}

Abbreviations: $\mathrm{Mf}=$ microfilaria; $\mathrm{L}_{1}=$ first-stage larva; $\mathrm{L}_{3}=$ third-stage larva (infective larva); $\mathrm{FL}=$ filarial nematode; $\mathrm{NFL}=$ non-filarial nematode; UID = unidentified nematode; ${ }^{*}$ black fly collections were conducted two times in this season.
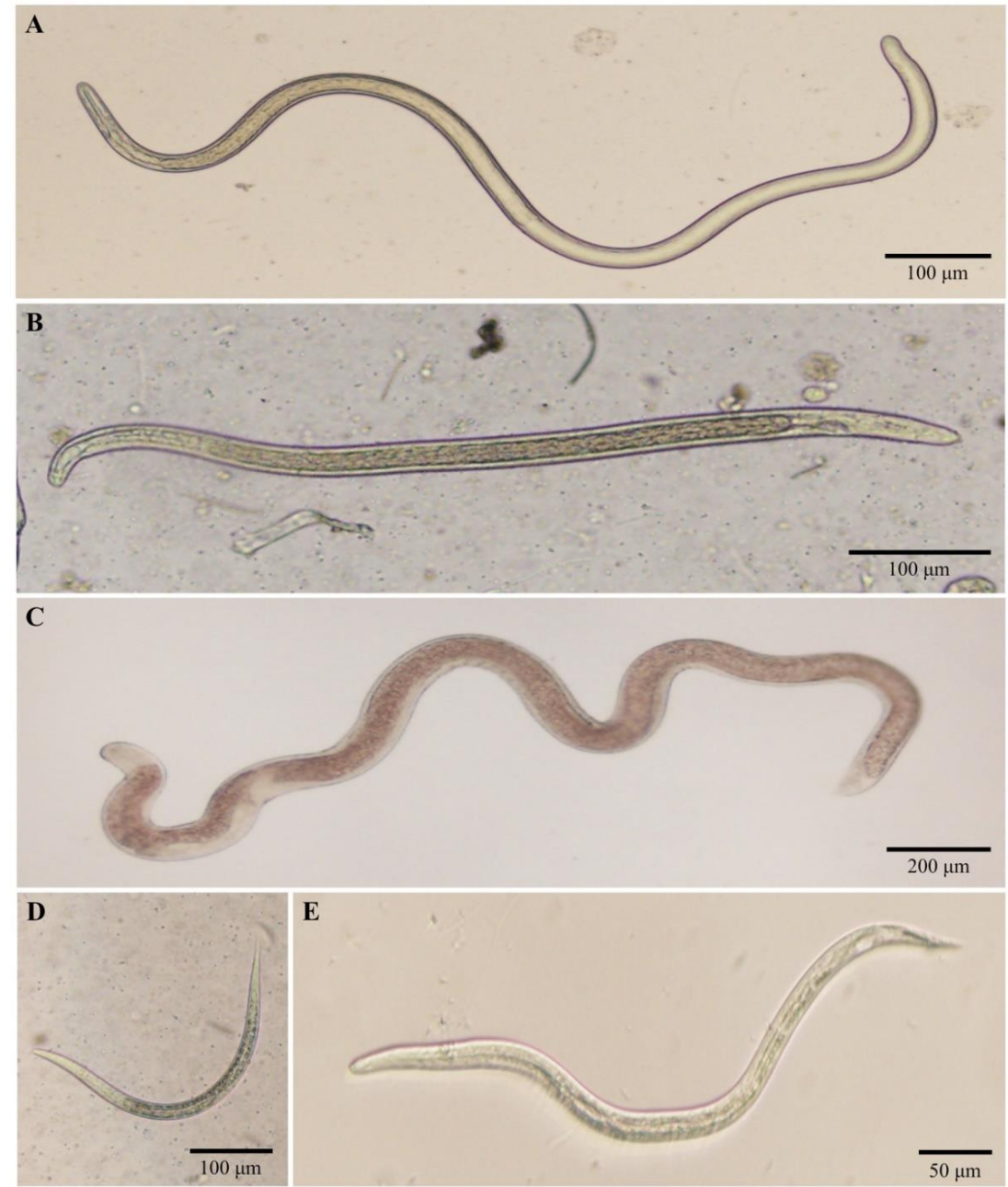

Figure 1. Filarial and non-filarial larvae recovered from thoraxes of adult female black flies. (A) $\mathrm{L}_{3}$ larva of Onchocerca sp. type I recovered from S. nigrogilvum. (B) $\mathrm{L}_{3}$ larva of an unknown filarial species recovered from three species in the $S$. asakoae species-group and Simulium sp. in the S. varicorne species-group. (C-E) $\mathrm{L}_{3}$ larvae of mermithid, rhabditida, and ascaridoid nematodes recovered from species in the $S$. asakoae species-group, respectively. 
Table 3. Measurements, stages, and molecular identification of filarial and non-filarial larvae recovered from adult female black flies collected from Ban Lek and Ban Pang Dang, Chiang Mai province, northern Thailand.

\begin{tabular}{|c|c|c|c|}
\hline Black Fly Species (No.). & Larval Stage (No.) & Body Length $\times$ Body Width $(\mu \mathrm{m})$ & $\begin{array}{c}\text { Molecular } \\
\text { Identification }\end{array}$ \\
\hline $\begin{array}{l}\text { Filarial nematodes } \\
\text { S. nigrogilvum (4) } \\
\text { S. asakoae species-group (3) } \\
\text { Simulium sp. (1) }\end{array}$ & $\begin{array}{l}\mathrm{L}_{3}(6) \\
\mathrm{L}_{3}(4) \\
\mathrm{L}_{1}(1)\end{array}$ & $\begin{array}{c}(1027.1-1339.5) \times(25.6-29.6) \\
(576.1-688.8) \times(26.9-28.6) \\
270.3 \times 18.6\end{array}$ & $\begin{array}{l}{ }^{1} \text { Onchocerca sp. type I } \\
{ }^{1} \text { Filarioid nematode } \\
{ }^{1} \text { Filarioid nematode }\end{array}$ \\
\hline $\begin{array}{l}\text { Non-filarial nematodes } \\
\text { S. asakoae species-group (3) }\end{array}$ & $\begin{array}{l}\mathrm{L}_{3}(1) \\
\mathrm{L}_{3}(1) \\
\mathrm{L}_{3}(1)\end{array}$ & $\begin{aligned} 2864.1 & \times 102.7 \\
446.4 & \times 20.3 \\
606.2 & \times 26.9\end{aligned}$ & $\begin{array}{l}{ }^{3} \text { Mermithid nematode } \\
2 \text { Rhabditida nematode } \\
{ }^{3} \text { Ascaridoid nematode }\end{array}$ \\
\hline $\begin{array}{l}\text { Unidentified nematodes } \\
\text { S. asakoae species-group (2) }\end{array}$ & $\begin{array}{l}\mathrm{Mf}(1) \\
\mathrm{L}_{1}(1)\end{array}$ & $\begin{array}{c}336.6 \times 9.6 \\
468.9 \times 16.2\end{array}$ & N/A \\
\hline
\end{tabular}

${ }^{1}$ Based on cox 1 and $12 \mathrm{~S}$ genes; ${ }^{2}$ based on the $12 \mathrm{~S}$ rRNA gene; ${ }^{3}$ based on the $18 \mathrm{~S}$ rRNA gene. Abbreviations: Mf $=$ microfilaria; $\mathrm{L}_{1}=$ first-stage larva; $\mathrm{L}_{3}=$ third-stage larva (infective larva); $\mathrm{N} / \mathrm{A}=$ not available.

\subsection{Molecular Identification of Recovered Larvae}

\subsubsection{Ban Lek}

Molecular species identification based on $\operatorname{cox} 1$ and $12 \mathrm{~S}$ rRNA gene sequences was performed for all thirteen infective larvae (including seven larvae from the preliminary study), and twelve of them were successfully amplified. The sequence fragments generated were 649 and $470-471$ bp long for the cox 1 and $12 \mathrm{~S}$ rRNA genes, respectively. Phylogenetic analyses revealed that $O$. sp. type I of our study formed a monophyletic clade with $O$. sp. type A recovered from S. bidentatum in Japan and $O$. sp. type I recovered from S. nigrogilvum in western Thailand (Figures 2 and 3). The very small genetic distance (K2P, cox1: $0.00-0.89 \% ; 12 \mathrm{~S}$ rRNA: $0.00-0.27 \%$ ) between the $O$. sp. type I isolated in this study and $O$. sp. type I (= type A) retrieved from GenBank strongly suggested that they were the same $O$. sp. Compared with other $O$. spp., our $O$. sp. type I sequences showed $9.43-12.96 \%$ and $5.34-10.80 \%$ sequence difference for cox 1 and $12 \mathrm{~S}$ rRNA genes, respectively.

\subsubsection{Ban Pang Dang}

The cox 1 and $12 S$ rRNA genes of all five unknown filarial larvae were successfully amplified. The sequence fragments generated were 649 and $464 \mathrm{bp}$ long for the cox 1 and 12S rRNA genes, respectively. Phylogenetic analyses based on both mitochondrial genes showed that all five larvae were clustered together and formed a monophyletic clade with high bootstrap support (Figures 2 and 3). They were placed as a sister group to Loa loa. Additionally, the sequence analysis of both genes using BLAST revealed that all larvae were closest to filarioid nematodes, i.e., Dirofilaria repens, Wuchereria bancrafti, Brugia malyai, and Loa loa, with $>89 \%$ sequence identity (Table S1). However, the genetic distance between our unknown filarioid nematodes and all filarioid nematodes for which the corresponding information was present in the databases was still rather high (K2P, cox1: 12.03-21.53\%; 12S rRNA: 8.70-14.40\%), suggesting that our unknown larvae represent a new species. 


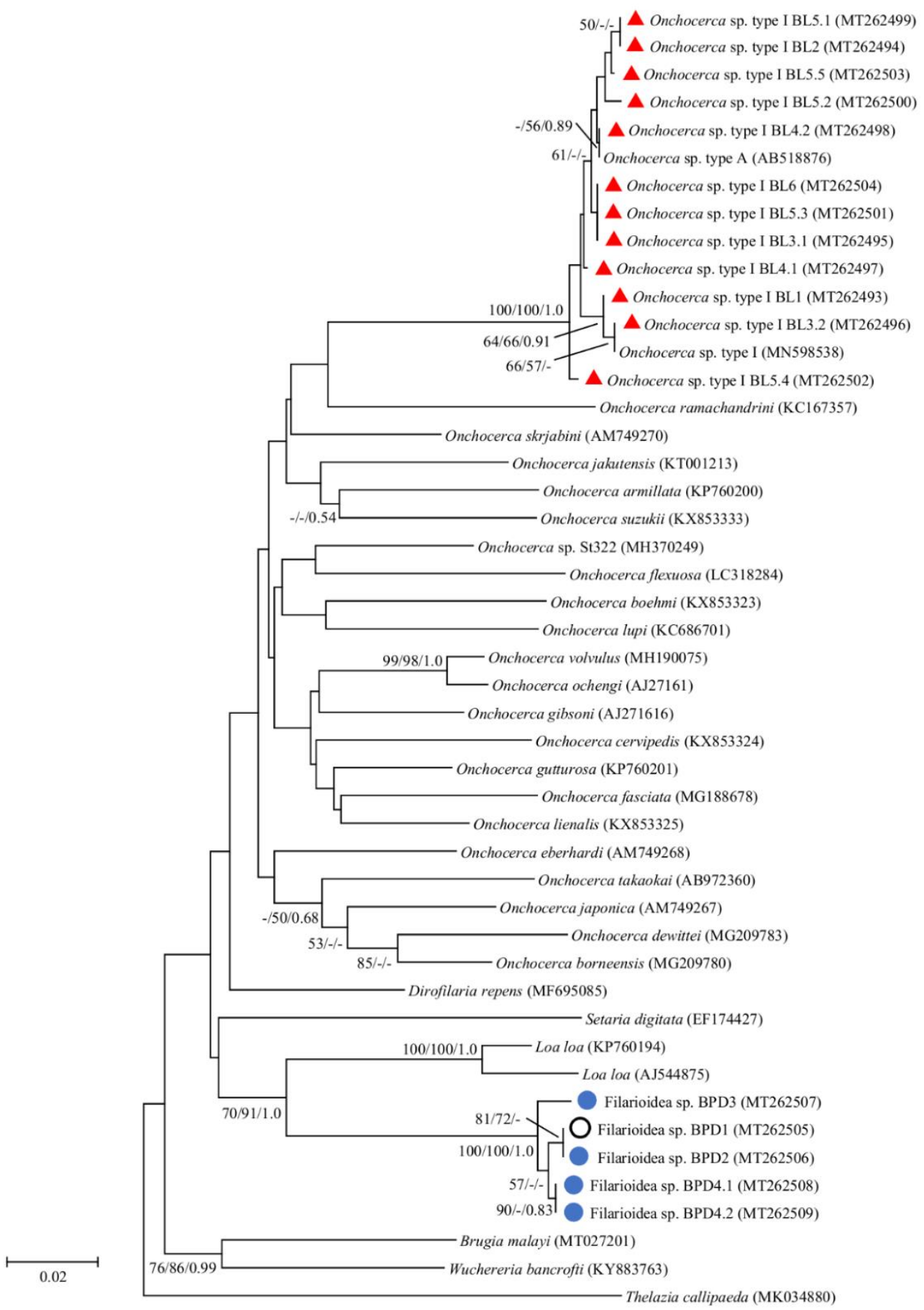

From Simulium nigrogilvum

From Simulium asakoae species-group

From Simulium varicorne species-group

Figure 2. Neighbor-joining tree of Onchocerca spp. and unknown filarial larvae based on the cox1 gene sequences. Bootstrap values and posterior probabilities (neighbor-joining (NJ)/maximum-likelihood (ML)/Bayesian inference (BI)) are shown above or near the branches. A dash indicates that support values are less than $50 \%$ (for NJ and ML) or 0.50 (for BI). The scale bar represents 0.02 substitutions per nucleotide position. Red triangles, blue circles, and white circle with a black border before each specimen designate the specimens obtained from this study and also indicate the vector blackfly species. 


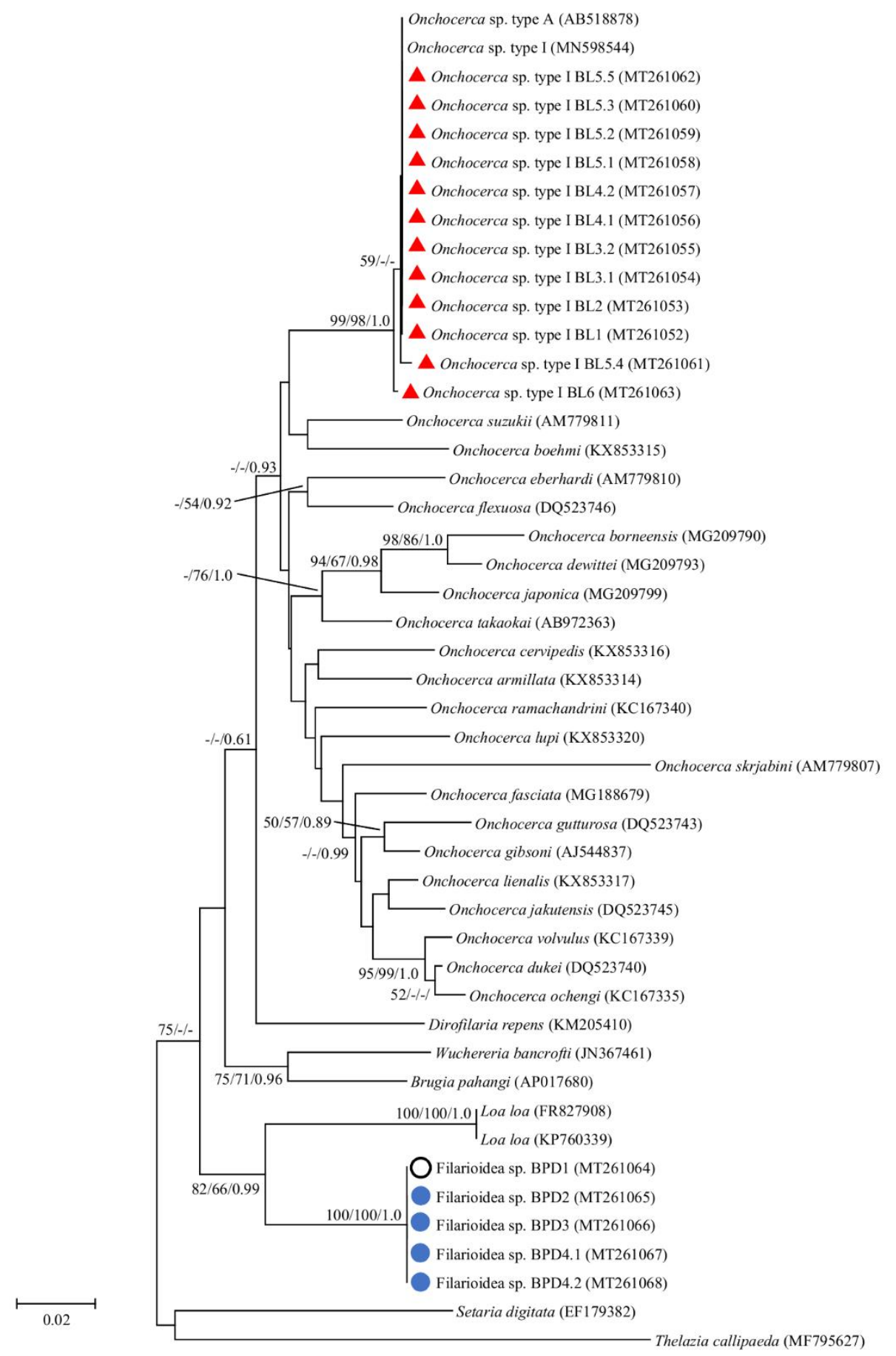

From Simulium nigrogilvum

From Simulium asakoae species-group $\bigcirc$ From Simulium varicorne species-group

Figure 3. Neighbor-joining tree of Onchocerca spp. and unknown filarial larvae based on the 12S rRNA gene sequences. Bootstrap values and posterior probabilities (NJ/ML/BI) are shown above or near the branches. A dash indicates that support values are less than $50 \%$ (for NJ and ML) or 0.50 (for BI). The scale bar represents 0.02 substitutions per nucleotide position. Red triangles, blue circles, and white circle with a black border before each specimen designate the specimens obtained from this study and also indicate the vector blackfly species. 
$\mathbf{A}$

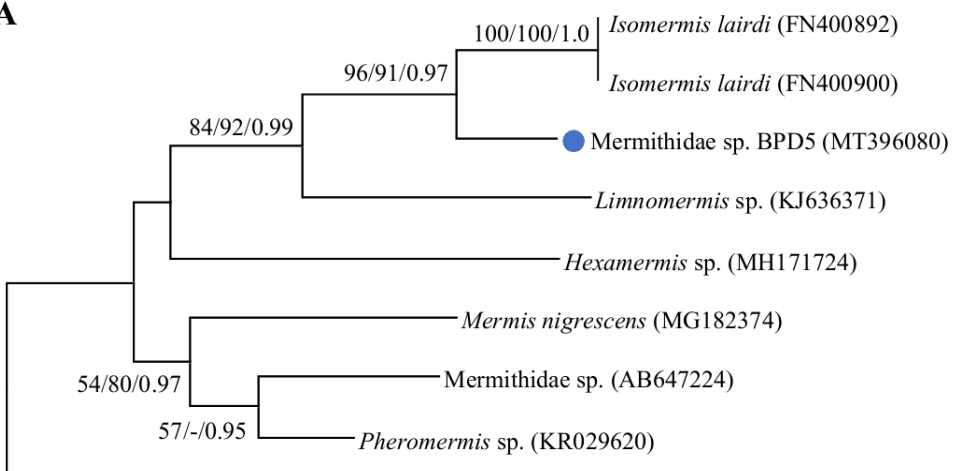

Clarkus papillatus (KJ769261)

0.01

B

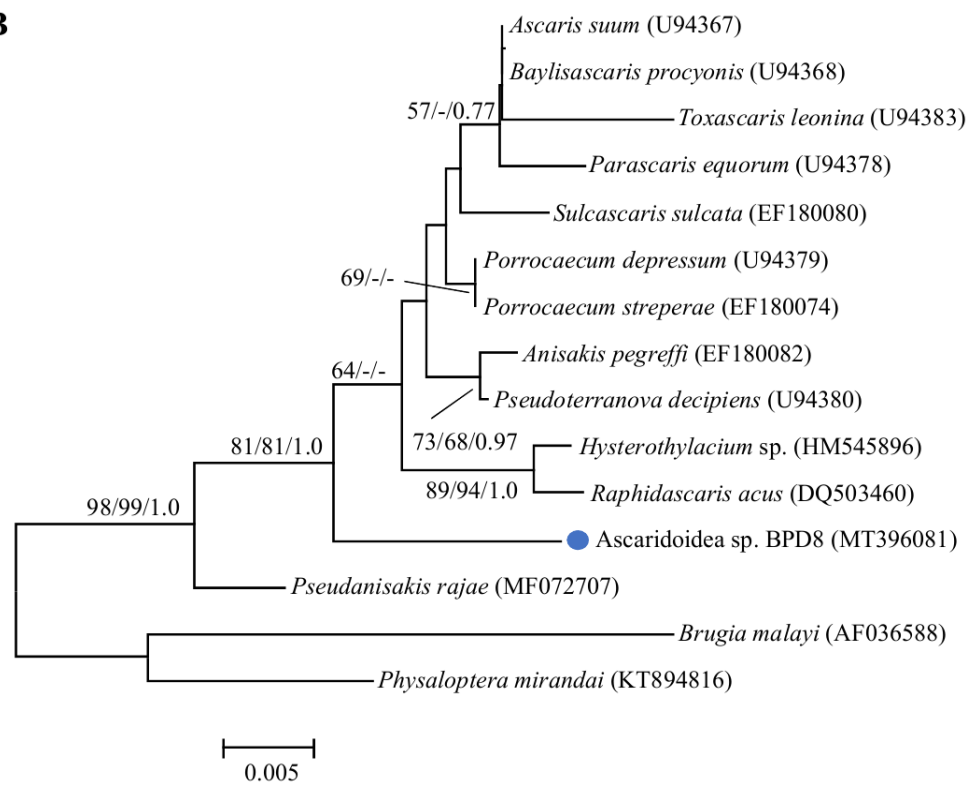

C

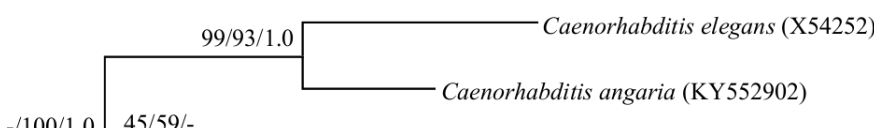

45/59/-

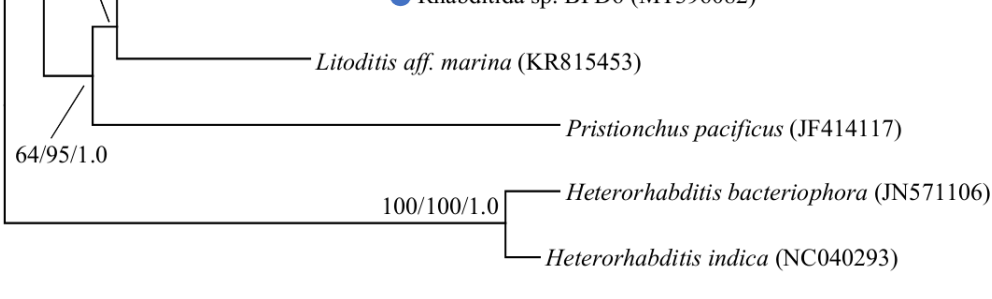

0.020 From Simulium asakoae species-group

Figure 4. Neighbor-joining trees of non-filarial nematodes. Bootstrap values and posterior probabilities (NJ/ML/BI) are shown above or near the branches. A dash indicates that support values are less than $50 \%$ (for $\mathrm{NJ}$ and ML) or 0.50 (for BI). Blue circles before each specimen designate the specimens obtained from this study and also indicate the vector blackfly species. (A) An 18S rRNA tree of mermithid nematodes. (B) An 18S rRNA tree of ascaridoid nematodes. (C) An 12S rRNA tree of rhabditida nematodes. 
For the three non-filarial larvae recovered from three flies in the $S$. asakoae species-group, an analysis of the $18 \mathrm{~S}$ rRNA sequence using BLAST and phylogenetic analyses revealed that they were indeed three different species of non-filarial nematodes. The first of the unknown nematodes resembling mermithid nematodes was highly similar (97\% sequence identity) to Isomermis lairdi, which is a known mermithid parasite of simuliids (Table S1). However, although the genetic differentiation between this mermithid nematode and I. lairdi was relatively low $(1.84 \%)$, in the phylogentic analyses, this mermithid nematode was separated with high bootstrap support from the published I. lairdi specimens, suggesting that it might be a different species (Figure 4A). The second of the unknown nematodes was highly similar to several ascaridoid nematode species, for example, Ascaris suum, Porrocaecum streperae, and Pseudoterranova decipiens, with $>97 \%$ sequence identity in the $18 \mathrm{~S}$ rRNA gene sequence (Table S1). The genetic divergence was moderate (1.96-3.21\%) and in the phylogenetic analyses, it was well-separated from all other ascaridoid nematode species retrieved from databases, suggesting that it also might be an unknown species (Figure 4B). The third of the unknown nematodes was genetically close to Litoditis aff. marina, with $90 \%$ sequence identity in the $12 \mathrm{~S}$ rRNA gene sequence (Table S1). With a genetic distance of 10.41-17.58\% between this rhabditida nemotode and its most closely related known species, it is likely that this worm also represents a novel species (Figure 4C).

\subsection{Molecular Identification of Infected Black Flies}

To confirm the exact species of infected black flies, molecular species identification based on cox 1 gene sequences was performed. All 13 infected black flies (S. nigrogilvum $(n=4)$, species in the S. asakoae species-group $(n=8)$, and $S$. sp. in the $S$. varicorne species-group $(n=1))$ were successfully amplified with a length of $658 \mathrm{bp}$. All six infected flies that had been morphologically identified as S. nigrogilvum formed a monophyletic group together with the $S$. nigrogilvum reference sequences retrieved from the database. This supported that they all were truly S. nigrogilvum. The S. nigrogilvum group was clearly separated from the closely related species Simulium umphangense (genetic distances 5.17-6.74\%) (Figure 5). The fly morphologically classified as unknown S. sp. in the S. varicorne species-group (BPD1) turned out to be genetically related to three members of the $S$. chumpornense subgroup, but was clearly separated from them (Figure 5). Simulium sp. (BPD1) was distinguished from S. chumpornense by $3.11-3.30 \%$, Simulium kuvangkadilokae by $1.99-2.36 \%$, and Simulium piroonae by $3.49-3.68 \%$. Based on these relatively high genetic distances between $S$. sp. and its most closely related species, this black fly is most likely a new species.

For the eight flies morphologically assigned to the $S$. asakoae species-group, the cox 1 sequences were compared with 11 other known species within the S. asakoae species-group. Based on phylogenetic analyses and comparisons of genetic distances, six flies were tentatively identified as belonging to four known species of the S. asakoae species-group, namely S. asakoae (BPD2 and BPD6), Simulium monglaense (BPD4 and BPD5), Simulium myanmarense (BPD3), and Simulium tanahrataense (BPD7) (Table S2, Figure 5). Two specimens (BPD8 and BPD9) most likely represent a new species in the $S$. asakoae species-group, as they formed a strongly supported monophyletic clade with a moderate to high genetic distance when compared to other known species (2.35-8.33\%) (Table S2, Figure 5). 


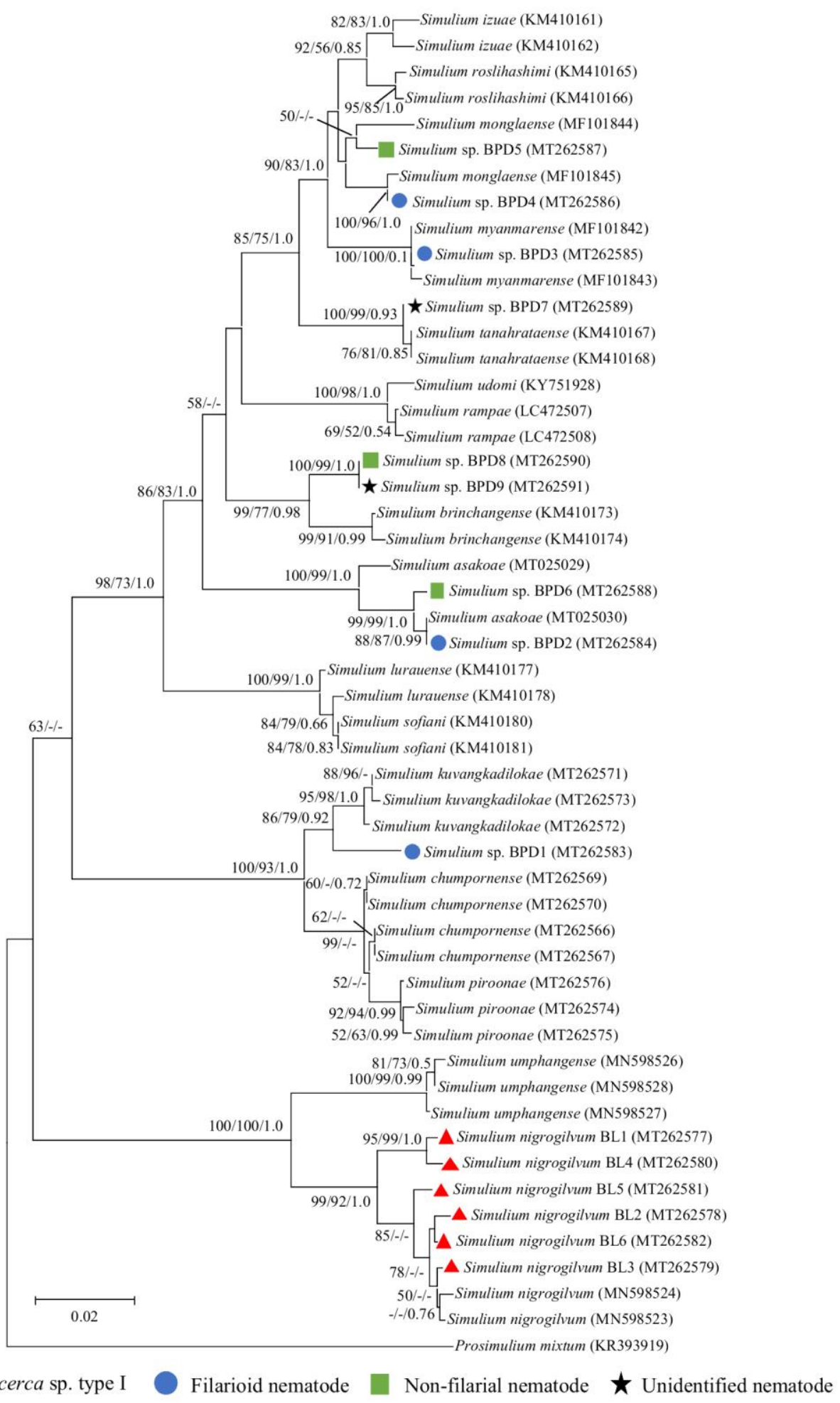

Figure 5. Neighbor-joining tree of infected black flies based on cox 1 gene sequences. Bootstrap values and posterior probabilities $(\mathrm{NJ} / \mathrm{ML} / \mathrm{BI})$ are shown above or near the branches. A dash indicates that support values are less than $50 \%$ (for $\mathrm{NJ}$ and $\mathrm{ML}$ ) or 0.50 (for BI). The scale bar represents 0.02 substitutions per nucleotide position. Red triangles, blue circles, green squares, and black stars before each specimen designate the specimens obtained from this study and also indicate the species/group of nematode larvae recovered. 


\section{Discussion}

Black flies are well-known to play the most important role in the transmission of zoonotic onchocerciasis to humans [2]. However, information on the transmission of this disease by black flies in Thailand is very limited. This study is the first to clarify the species status of filarial parasites and their black fly vectors in the Chiang Mai province, northern Thailand, using a combined approach of morphotaxonomic and molecular analyses. Information obtained from this study will be useful in planning the preventive measurements of human zoonotic onchocerciasis that may occur in the country in the future. In addition, we collected black fly samples at two study sites which have different elevations. Our findings are in agreement with a previous study conducted by Srisuka et al. [18], who reported that the elevation influences the presence or absence of particular black fly species in Thailand. On the other hand, we also found examples for non-altitude-dependent species. For example, the $S$. asakoae species-group was widely distributed from low elevations to $1600 \mathrm{~m}$ in high mountains. In the first study area (Ban Lek, high elevation), seven black fly taxa were collected. Among these, the S. asakoae species-group, S. chamlongi, the S. doipuiense complex, and S. nigrogilvum have been reported as human-biting species in previous studies [11,19-21]. The Simulium doipuiense complex was only collected from high elevations above sea level, similar to previous studies by Ittiponpanya [19] and Pramual et al. [21], who also found this species at high elevations (range between 1200 and $1600 \mathrm{~m}$ ). Simulium chumpornense and S. nigrogilvum were the predominant taxa, consistent with Srisuka et al. [18], who noted that a large number of adult female flies of these species were collected, although no larvae and pupae were found in this area.

To date, in Thailand, only one previously undescribed Onchocerca sp. (O. sp. type I) has been confirmed to infect $S$. nigrogilvum based on morphological characterization and DNA sequence analyses [16]. Similarly, our study revealed that S. nigrogilvum, collected at Ban Lek is a natural vector of $O$. sp. type I, which has previously been isolated from S. bidentatum in Japan and S. nigrogilvum in western Thailand $[15,16]$. Simulium nigrogilvum has been regarded as a natural vector for possible zoonotic onchocerciasis by $O$. sp. type I because it harbors the infective stage $\left(\mathrm{L}_{3}\right)$ of the disease agent and prefers to feed on humans (anthropophily) [9]. Furthermore, O. sp. type I has a broad geographical distribution, as it has been found from Thailand to Kyushu and Honshu in Japan [15,16]. In Thailand, cattle or water buffaloes (or both) are suspected to be reservoir hosts of this $O$. sp., owing to the fact that other ungulates were absent in and around the study area [13]. Natural filarial infections were found throughout the year, except for the dry-cool season, in which only a very low number of black flies were collected. The infection rate of $O$. sp. type I in S. nigrogilvum was slightly higher $(1.3 \%)$ than in a previous study $(0.8 \%)$ conducted in western Thailand [16].

In the second area (Ban Pang Dang, low elevation), among the nine black fly taxa captured, the $S$. asakoae species-group was the predominant one. This finding was consistent with previous reports by Takaoka et al. [11] and Ishii et al. [12], who studied the daily biting activity patterns and natural filarial infections of adult black flies in Doi Saket district, Chiang Mai province. In this area, natural infections were observed in all seasons, but only the S. asakoae species-group and S. sp. were found to be natural vectors of filarial and/or non-filarial nematodes. The pig farm in this area may influence (1) the species composition of black flies, if some black fly species show a preference for pigs as a blood-meal host, and (2) the species of Onchocerca larvae carried by black flies. However, there is no information about Onchocerca infections in pigs in Thailand or other countries. Hence, further studies are needed to elucidate whether the filarial larvae and/or the non-filarial larvae found in black flies in this study affect livestock or local wildlife.

In this study, based on DNA sequence analyses of two mitochondrial genes, one species of unknown filarial nematode was found to infect three species in the $S$. asakoae species-group and S. sp. in the S. varicorne species-group. We followed the criteria for distinguishing different species of filarioid nematodes (cox1 interspecific distances $>4.8 \%$ ) suggested by Ferri et al. [22] and Onchocerca spp. (interspecific distances $>4.5 \%$ ) suggested by Lefoulon et al. [5]. Interestingly, comparing sequences of cox 1 and 12S rRNA genes between five filarial nematodes recovered from species in the S. asakoae 
species-group and S. sp., and other filarioid nematodes suggested that they all represent the same new species. The phylogenetic trees of both genes showed that our filarial nematodes were separated from other filarioid nematodes, including the cryptic Onchocerca species infecting cervids in the USA [23] and the recently identified Onchocerca species, O. borneensis, which was discovered from the Bornean bearded pig (Sus barbatus) in Malaysia by Uni et al. [6].

We also found that the positive female of $S$. sp. in the S. varicorne species-group (BPD1) was most likely to be a new black fly species belonging to the $S$. chumpornense subgroup. Due to the limited sample size, further taxonomic and molecular analyses are needed to clarify the species status of this female.

Due to the morphological similarities of the $S$. asakoae species-group, which may lead to misidentification, we determined the species status of our positive samples belonging to this species-group based on an analysis of the cox1 gene sequences. Two positive samples (BPD2 and BPD6) were true S. asakoae, supported by their genetic divergence that fell into the range of intraspecific divergence described for S. asakoae (0-2.27\%) [24]. Besides S. asakoae, our positive samples seemed to be comprised of three known species (S. monglaense, S. myanmarense, and S. tanahrataense) and one unknown species in the $S$. asakoae species-group. Similar to the recent study of Jomkumsing et al. [25], who recorded S. monglaense and S. myanmarense from Thailand based on cox 1 gene sequences, we tentatively identified the distribution of these two black fly species in Chiang Mai province, northern Thailand, based on the same gene sequences. Additionally, based on cox1 gene sequences, our study is the first to record S. tanahrataense in Thailand, although the species identification is only supported by molecular data (very low genetic divergence $(0.18 \%)$ between our sample and true S. tanahrataense, and relatively high divergences (4.23-7.75\%) with 10 other known species of the $S$. asakoae species-group). We also suggest that two positive samples (BPD8 and BPD9) are a distinct species near S. brinchangense in the S. asakoae species-group, although the genetic divergence between this new species and S. brinchangense was only $2.35-2.73 \%$, which is less than the $3.0 \%$ proposed as cutoff genetic divergence for delimiting species boundaries in black flies [26-28]. When using a single gene, such as cox1, for black fly species identification, one has to be careful because of possible misidentification. In some cases, cox 1 gene sequences failed to differentiate two closely related species of the $S$. asakoae species-group. For example, the $\operatorname{cox} 1$ gene sequences of $S$. udomi and $S$. rampae were almost identical and the genetic divergence between these two species was only $0.71-0.89 \%$ (Table S2). Therefore, in order to definitely conclude that these black fly species are actually present in Thailand, an integrated approach of morphotaxonomic and multi-locus sequence analyses is required.

Three different taxa of non-filarial nematodes classified by morphological characters were also found to infect three species of the $S$. asakoae species-group. The first taxon is molecularly similar to I. lairdi, which is a mermithid nematode. Although a small genetic distance $(1.84 \%)$ was observed between our specimen and I. lairdi, we regard it as a distinct species based on the combination of morphological and molecular data. The low genetic differentiation observed was not unexpected, since the $18 \mathrm{~S}$ rRNA gene is generally highly conserved [29]. For example, the variation of $18 \mathrm{~S}$ rRNA gene sequences between different Romanomermis spp., the entomopathogenic nematodes of mosquito larvae, was only $0.4 \%$ [30]. In Thailand, only one publication has reported mermithid nematodes in black flies [31]. The investigators demonstrated that the larvae of five black fly species (S. chiangmaiense, S. fenestratum, S. nakhonense, S. quinquestriatum, and S. tani) were infected with single or multiple mermithid nematodes. However, the species of those mermithid nematodes had never been determined based on molecular data until the present study. The second taxon is most likely to be an unrecognized species belonging to the family Ascarididae and separated from all other ascaridoid nematodes in the 18S rRNA phylogenetic tree. Also considering the ornithophilic behavior of the S. asakoae species-group $[9,12]$, it is probable that this worm belongs to the genus Porrocaecum, species of which are reported worldwide as common bird parasites [32]. As in mermithid nematodes, a low interspecific variation of the $18 \mathrm{~S}$ locus was also observed between our specimen and several species of ascaridoid nematodes. More variable gene regions, which were highly effective for differentiating between closely 
related species, such as cox1, cox2, or ITS1, are required for resolving the taxonomic relationship between these nematodes [33]. The third taxon seems to be an unrecognized rhabditida nematode of the class Chromadorea based on $12 \mathrm{~S}$ rRNA gene sequence data. Nevertheless, more molecular data are needed as the $12 \mathrm{~S}$ rRNA phylogenetic tree revealed an unclear taxonomic relationship for this worm. More conserved gene regions, such as the 18S rRNA gene, which we unfortunately failed to amplify for this specimen, should be useful for resolving more distant taxonomic relationships [33]. Additionally, the infection rates of filarial and non-filarial nematodes in the $S$. asakoae species-group were similar to a previous study, in which at least two different species of non-filarial nematodes were found [10,12].

Apart from avian species (birds and chickens), suidae might also be a reservoir host of these filarial and non-filarial nematodes, because the black fly vectors in the S. asakoae species-group were collected in a pig farming area and swine (Sus scrofa domesticus) was also used as bait. Therefore, further studies to search for the adult stages of our parasites in the definitive host are needed.

Interestingly, females of $S$. chumpornense were collected in an extremely high number in the hot season (March) in both study areas, but rapidly disappeared after that. We assume that the outbreak of this black fly species may have been the result of the high temperature in the hot season, as well as a forest fire near the study areas during the black fly collections. These factors may affect the habitat and/or host-seeking behavior of this black fly species.

\section{Materials and Methods}

\subsection{Ethics Statement}

The protocol of this study was approved by the Research Ethics Committee (Institutional Animal Care and Use Committee) (Protocol Number 46/2561) and the Institutional Biosafety Committee (Approval No. CMUIBC02019/2562) of the Faculty of Medicine, Chiang Mai University, Chiang Mai province, Thailand.

\subsection{Study Areas and Adult Female Black Fly Collections}

Adult black fly collections were carried out at two selected sites in Chiang Mai province, northern Thailand (Figure 6). The first selected site was an open grassland located in Ban Lek village $\left(20^{\circ} 04^{\prime} 36.3^{\prime \prime} \mathrm{N}\right.$ $99^{\circ} 10^{\prime} 53.0^{\prime \prime} \mathrm{E}, 1571 \mathrm{~m}$ in elevation), Fang district. The second selected site was in a pig farming area

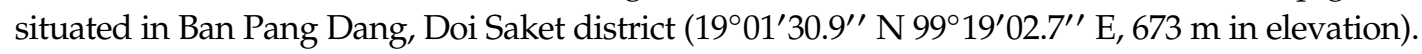

Female adult black flies were captured two times each seasonally from March 2018 to January 2019 (hot-dry: March-June; rainy: August-October; cool-dry: November-January) by using a sweep net while flying around each human or animal (swine) bait. Each collection lasted for $2 \mathrm{~h}$ from 7.00-9.00 $\mathrm{h}$ in the early morning, which is a period of time in which most black fly species prefer to seek blood meal sources and attract hosts. They were kept in a paper cup with a pad of cotton wool soaked with $10 \%$ sucrose solution placed on the top-screen, and then stored in a humid chamber. After being transported to the Department of Parasitology, Faculty of Medicine, Chiang Mai University, Chiang Mai province, Thailand, they were morphologically identified, before being dissected and examined for filarial larvae.

\subsection{Morphological and Molecular Identification of Female Black Flies}

Adult female black flies caught were knocked out on ice for approximately $10 \mathrm{~min}$ and morphologically identified under a stereomicroscope using the standard keys of Takaoka et al. [34]. In addition, DNA barcoding based on the $\operatorname{cox} 1$ gene was conducted to confirm the species of the infected flies. In brief, the total DNA of individual files was extracted using the PureLink ${ }^{\circledR}$ Genomic DNA Mini Kit (Invitrogen, Carlsbad, CA, USA). The mitochondrial cox1 gene was amplified using a universal primer set: LCO1490 (5'-GGT CAA CAA ATC ATA AAG ATA TTG G-3') and HCO2198 (5'-TAA ACT TCA GGG TGA CCA AAA AAT CA) [35]. DNA amplification was carried out with the reaction mixture $(20 \mu \mathrm{L})$ containing $1-2 \mu \mathrm{L}$ of DNA template, $0.5 \mathrm{U}$ of Taq DNA polymerase, $3 \mathrm{mM}$ of 
$\mathrm{MgCl}_{2}, 0.25 \mathrm{mM}$ dNTPs, and $0.2 \mu \mathrm{M}$ of each primer under the PCR cycling parameters previously described by Conflitti et al. [36]. PCR fragments were visualized on 1.5\% agarose gels stained with SYBR Safe DNA gel stain (Invitrogen, Carlsbad, CA, USA). The PCR products were then sent to Macrogen, Inc. (Seoul, Korea) to purify and sequence them in both directions using the same primers as in PCR by a 3130 genetic analyzer (Applied Biosystems, Foster, CA, USA).

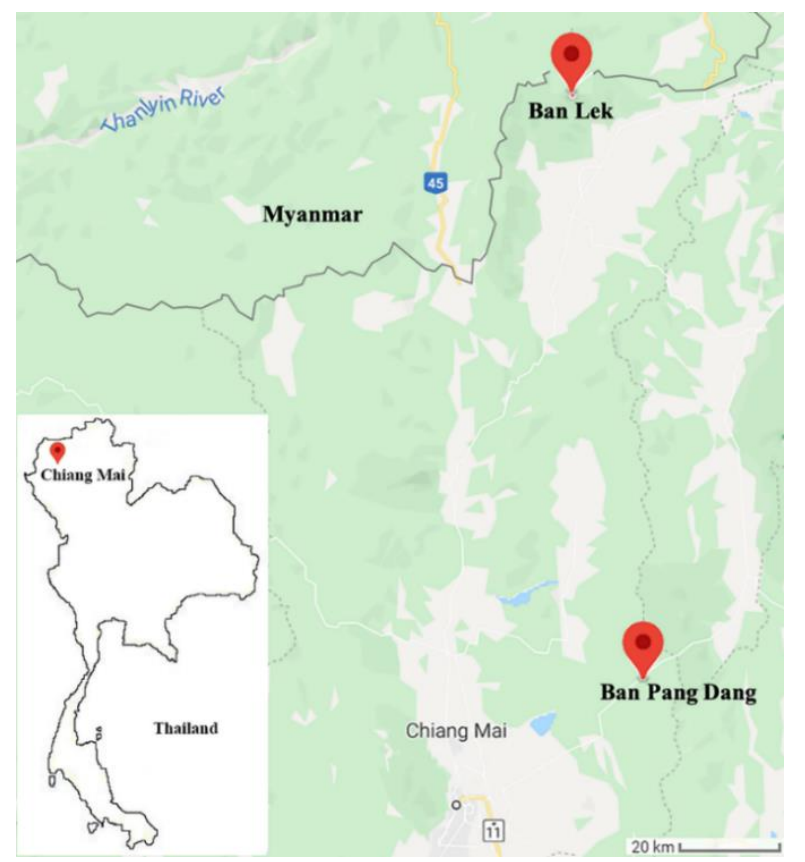

Figure 6. Map of two study areas in Chiang Mai province, northern Thailand, where black fly samples were collected.

Both forward and reverse sequences were assembled and edited manually in the MEGA Version 7.0 program [37]. Sequence alignment was performed using the ClustalW multiple alignment programs [38]. Gap sites were treated as missing data for the following analyses.

Phylogenetic trees based on the $\operatorname{cox} 1$ gene sequences were constructed using neighbor-joining (NJ), maximum-likelihood (ML), and Bayesian inference (BI) methods. The best-fit models for ML and BI methods were selected using the jModelTest version 2.1.10 program [39]. The NJ tree was built with the MEGA version 7.0 program [37]. Bootstrap values for supporting each clade node were calculated using the bootstrapping method with 1000 replicates. The ML tree was developed using PhyML 3.3 with 100 bootstrap replicates [40]. BI was performed in MrBayes v.3.2.7 [41] and run for at least two million generations or until the ASDSF was less than 0.01 with sampling every 100 generations and a burnin of $25 \%$. Genetic divergences within and between species were estimated using Kimura's two-parameter (K2P) model [42]. The DNA sequence of Prosimulium mixtum was used as the outgroup for all analyses.

\subsection{Dissections of Black Flies and Morphological and Molecular Identification of Recovered Larvae}

After species identification, individual flies were dissected to search for filarial larvae on a glass slide in a drop of PBS pH 7.4 or $0.9 \%$ NSS under a stereomicroscope at $10 \times$ magnification. The unknown larvae recovered were observed, measured, and identified to a genus level following the identification key of Bain and Chabaud [17] under a compound microscope, Olympus BX53 (Olympus, Shinjuku, TYO, Japan). Subsequently, they were preserved in $80 \%$ ethanol and kept at $-20{ }^{\circ} \mathrm{C}$ until being used for molecular analysis. Descriptive statistics were used to calculate the percentage of infection rate.

The unknown larvae recovered were molecularly identified using mitochondrial cox 1 and $12 \mathrm{~S}$ rRNA genes. In some cases, in which the amplification of both mitochondrial genes failed, the nuclear 
$18 S$ rRNA (SSU HVR-I) gene was used instead. The specimens of Onchocerca sp. type I $(n=6)$ recovered from $S$. nigrogilvum from our preliminary study were also included for molecular analysis. Genomic DNA of individual larvae was extracted using the PureLink ${ }^{\circledR}$ Genomic DNA Mini Kit (Invitrogen, Carlsbad, CA, USA). PCR amplification was conducted by using the primers and annealing temperatures listed in Table 4 with the reaction mixture of $20 \mu \mathrm{L}$, consisting of 1-2 $\mu \mathrm{L}$ of DNA template, $0.5 \mathrm{U}$ of Taq DNA polymerase, $2-3 \mathrm{mM}$ of $\mathrm{MgCl}_{2}, 0.25 \mathrm{mM}$ dNTPs, and $0.2 \mu \mathrm{M}$ of each primer under PCR cycling conditions described elsewhere [15,43]. The amplified products were purified and sequenced following the methods mentioned in Section 4.3.

Table 4. Details of primers used for amplifying mitochondrial and nuclear genes of recovered larvae.

\begin{tabular}{|c|c|c|c|c|c|c|}
\hline Region Amplified & & & Sequence $\left(5^{\prime}-3^{\prime}\right)$ & $\begin{array}{l}\text { Annealing } \mathrm{T} \\
\left({ }^{\circ} \mathrm{C}\right)\end{array}$ & Product (bp) & Ref \\
\hline $\operatorname{cox} 1$ & $\begin{array}{l}\text { Fw } \\
\text { Rev }\end{array}$ & $\begin{array}{l}\text { COIintF } \\
\text { COIintR }\end{array}$ & $\begin{array}{l}\text { TGATTGGTGGTTTTGGTAA } \\
\text { ATAAGTACGAGTATCAATATC }\end{array}$ & 48 & $\sim 689$ & [44] \\
\hline $12 \mathrm{~S}$ rRNA & $\begin{array}{l}\text { Fw } \\
\text { Rev }\end{array}$ & $\begin{array}{l}12 \mathrm{SF} \\
12 \mathrm{SR}\end{array}$ & $\begin{array}{l}\text { GTTCCAGAATAATCGGCT } \\
\text { ATTGACGGATGRTTTGTACC }\end{array}$ & 50 & $\sim 502$ & [45] \\
\hline 18S rRNA (SSU HVR-I) & $\begin{array}{l}\text { Fw } \\
\text { Rev }\end{array}$ & $\begin{array}{l}\text { RS5401 } \\
\text { RS5402 }\end{array}$ & $\begin{array}{l}\text { AAAGATTAAGCCATGCATG } \\
\text { CATTCTTGGCAAATGCTTTCG }\end{array}$ & 50 & $\sim 919$ & [43] \\
\hline
\end{tabular}

Abbreviations: $\mathrm{Fw}$ = forward primer; Rev = reverse primer; $\mathrm{T}$ = temperature; Ref = reference.

After DNA sequencing, the aligned cox1, 12S rRNA, and 18S rRNA gene sequences of the filarial and non-filarial larvae were used to construct the phylogenetic trees separately for each gene using the procedures described in Section 4.3. Thelazia callipaeda was used as the outgroup species for all analyses of the filarial nematodes. For an 18S rRNA phylogenetic tree of mermithid and ascaridoid nematodes, Clarkus papillatus and Brugia malay and Physaloptera mirandai were used as the outgroup species for all analyses, respectively. Moreover, Heterorhabditis bacteriophora and Heterorhabditis indica were used as the outgroup species for all analyses of the $12 \mathrm{~S}$ rRNA phylogenetic tree of rhabditida nematodes. For comparison, selected published sequences with the corresponding accession numbers listed in Figures 2-4 were included in the analysis.

Additionally, all of the sequences generated were compared with available sequences deposited in GenBank using the Basic Local Alignment Search Tool (BLAST) and were registered in the National Center for Biotechnology Information (NCBI) GenBank database under the following accession numbers: MT262563-MT262591, MT262493-MT262509, MT261052-MT261068, and MT396080-MT396082.

\section{Conclusions}

We discovered an unknown filarial species (probably a new species) in S. asakoae, S. myanmarense, and S. monglaense (all genetically identified) in the S. asakoae species-group, and S. sp. in the S. varicorne species-group, and also confirmed the presence of $O$. sp. type I in S. nigrogilvum collected in the Chiang Mai province, Thailand. In addition, three species of unknown non-filarial nematodes were found in S. asakoae, S. monglaense, and S. sp. in the S. asakoae species-group. Due to the limited sample size and ambiguous species status of these non-filarial larvae, further study is required to clarify whether they have the potential to be pathogens to humans. Unidentified nematodes were also obtained from S. tanahrataense and S. sp. in the S. asakoae species-group.

The fact that $S$. nigrogilvum and species in the S. asakoae species-group are anthropophilic and natural vectors of filarial worms, though their infection rates were low, suggests that people who visit or live in these areas are at risk of zoonotic filarial infections, particularly during the hot and rainy seasons.

Supplementary Materials: The following are available online at http://www.mdpi.com/2076-0817/9/6/512/s1: Table S1: NCBI BLAST results of filarial and non-filarial nematodes recovered from Simulium spp. based on mitochondrial cox1, 12S rRNA, and nuclear 18S rRNA (SSU HVR-I) gene sequences; Table S2: Range of interspecific genetic divergence $(\%)$ among the infected black flies belonging to the $S$. asakoae species-group. 
Author Contributions: Conceptualization, A.S. (Atiporn Saeung); methodology, K.A. and A.S. (Atiporn Saeung); formal analysis, K.A. and A.S. (Atiporn Saeung); investigation, K.A., W.S., and A.S. (Atiporn Saeung); resources, W.S. and A.S. (Atiporn Saeung); writing-original draft preparation, K.A. and A.S. (Atiporn Saeung); writing-review and editing, K.A., A.S. (Atiporn Saeung), W.S., M.F., A.S. (Adrian Streit), and H.T.; supervision, H.T.; project administration, A.S. (Atiporn Saeung); funding acquisition, A.S. (Atiporn Saeung). All authors have read and agreed to the published version of the manuscript.

Funding: This research was funded by the Thailand Science Research and Innovation (formerly known as the Thailand Research Fund) through the Royal Golden Jubilee Ph.D. Program, grant number: PHD/0094/2559 to A.S. for K.A.

Acknowledgments: We would like to thank Watchara Jatuwattana and Kanchon Pusawang for their assistance in the laboratory.

Conflicts of Interest: The authors declare no conflict of interest. The funders had no role in the design of the study; in the collection, analyses, or interpretation of data; in the writing of the manuscript; or in the decision to publish the results.

\section{References}

1. Crosskey, R.W. The Natural History of Blackflies; Wiley: Chichester, UK, 1990; p. 711.

2. Takaoka, H.; Fukuda, M.; Otsuka, Y.; Aoki, C.; Uni, S.; Bain, O. Blackfly vectors of zoonotic onchocerciasis in Japan. Med. Vet. Entomol. 2012, 26, 372-378. [CrossRef] [PubMed]

3. Fukuda, M.; Uni, S.; Igari, T.; Utsumi, Y.; Otsuka, Y.; Nakatani, J.; Uga, S.; Hara, T.; Hasegawa, H.; Takaoka, H. Human case of Onchocerca dewittei japonica infection in Fukushima, Northeastern Honshu, Japan. Parasitol. Int. 2019, 72, 101943. [CrossRef] [PubMed]

4. Wesolowska, M.; Zajac-Pytrus, H.; Masny, A.; Pytrus, W.; Knysz, B.; Golab, E.; Salamatin, R. Onchocerca jakutensis ocular infection in Poland: A new vector-borne human health risk? Parasit. Vectors 2020, $13,61$. [CrossRef]

5. Lefoulon, E.; Giannelli, A.; Makepeace, B.L.; Mutafchiev, Y.; Townson, S.; Uni, S.; Verocai, G.G.; Otranto, D.; Martin, C. Whence river blindness? The domestication of mammals and host-parasite co-evolution in the nematode genus Onchocerca. Int. J. Parasitol. 2017, 47, 457-470. [CrossRef]

6. Uni, S.; Mat Udin, A.S.; Agatsuma, T.; Junker, K.; Saijuntha, W.; Bunchom, N.; Fukuda, M.; Martin, C.; Lefoulon, E.; Labat, A.; et al. Description, molecular characteristics and Wolbachia endosymbionts of Onchocerca borneensis Uni, Mat Udin \& Takaoka n. sp. (Nematoda: Filarioidea) from the Bornean bearded pig Sus barbatus Müller (Cetartiodactyla: Suidae) of Sarawak, Malaysia. Parasit. Vectors 2020, 13, 50. [CrossRef] [PubMed]

7. Jumpato, W.; Tangkawanit, U.; Wongpakam, K.; Pramual, P. Molecular detection of Leucocytozoon (Apicomplexa: Haemosporida) in black flies (Diptera: Simuliidae) from Thailand. Acta Trop. 2019, 190, 228-234. [CrossRef]

8. Thaijarern, J.; Tangkawanit, U.; Wongpakam, K.; Pramual, P. Molecular detection of Trypanosoma (Kinetoplastida: Trypanosomatidae) in black flies (Diptera: Simuliidae) from Thailand. Acta Trop. 2019, 200, 105196. [CrossRef]

9. Pramual, P.; Thaijarern, J.; Tangkawanit, U.; Wongpakam, K. Molecular identification of blood meal sources in black flies (Diptera: Simuliidae) suspected as Leucocytozoon vectors. Acta Trop. 2020, 205, 105383. [CrossRef]

10. Fukuda, M.; Choochote, W.; Bain, O.; Aoki, C.; Takaoka, H. Natural infections with filarial larvae in two species of black flies (Diptera: Simuliidae) in northern Thailand. Jpn. J. Trop. Med. Hyg. 2003, 31, 99-102. [CrossRef]

11. Takaoka, H.; Choochote, W.; Aoki, C.; Fukuda, M.; Bain, O. Black flies (Diptera: Simuliidae) attracted to humans and water buffalos and natural infections with filarial larvae, probably Onchocerca sp., in northern Thailand. Parasite 2003, 10, 3-8. [CrossRef]

12. Ishii, Y.; Choochote, W.; Bain, O.; Fukuda, M.; Otsuka, Y.; Takaoka, H. Seasonal and diurnal biting activities and zoonotic filarial infections of two Simulium species (Diptera: Simuliidae) in northern Thailand. Parasite 2008, 15, 121-129. [CrossRef] [PubMed]

13. Takaoka, H.; Bain, O. Infections of blackflies (Diptera: Simuliidae) with three types of zoonotic Onchocerca larvae in Oita, Japan. Jpn. J. Trop. Med. Hyg. 1990, 18, 1-10. [CrossRef] 
14. Fukuda, M.; Takaoka, H.; Uni, S.; Bain, O. Infective larvae of five Onchocerca species from experimentally infected Simulium species in an area of zoonotic onchocerciasis in Japan. Parasite 2008, 15, 111-119. [CrossRef] [PubMed]

15. Fukuda, M.; Otsuka, Y.; Uni, S.; Bain, O.; Takaoka, H. Molecular identification of infective larvae of three species of Onchocerca found in wild-caught females of Simulium bidentatum in Japan. Parasite 2010, 17, 39-45. [CrossRef] [PubMed]

16. Saeung, A.; Srisuka, W.; Aupalee, K.; Fukuda, M.; Otsuka, Y.; Taai, K.; Maleewong, W.; Takaoka, H. Natural infections with larvae of Onchocerca species type I in the human-biting black fly, Simulium nigrogilvum (Diptera: Simuliidae), in western Thailand. Acta Trop. 2020, 204, 105344. [CrossRef] [PubMed]

17. Bain, O.; Chabaud, A.G. Atlas of infective larvae of filariae. Trop. Med. Parasitol. 1986, 37, 301-340. [PubMed]

18. Srisuka, W.; Takaoka, H.; Otsuka, Y.; Fukuda, M.; Thongsahuan, S.; Taai, K.; Choochote, W.; Saeung, A. Seasonal biodiversity of black flies (Diptera: Simuliidae) and evaluation of ecological factors influencing species distribution at Doi Pha Hom Pok National Park, Thailand. Acta Trop. 2015, 149, 212-219. [CrossRef]

19. Ittiponpanya, N. A whole-year study of the flying activity of black fly attracted to humans in Doi Suthep-Pui National Park. MSc Thesis, Chiang Mai University, Chiang Mai, Thailand, 2006.

20. Choochote, W.; Takaoka, H.; Fukuda, M.; Otsuka, Y.; Aoki, C.; Eshima, N. Seasonal abundance and daily flying activity of black flies (Diptera: Simuliidae) attracted to human baits in Doi Inthanon National Park, northern Thailand. Med. Entomol. Zool. 2005, 56, 335-348. [CrossRef]

21. Pramual, P.; Thaijarern, J.; Wongpakam, K. DNA barcoding of human-biting black flies (Diptera: Simuliidae) in Thailand. Acta Trop. 2016, 164, 33-40. [CrossRef]

22. Ferri, E.; Barbuto, M.; Bain, O.; Galimberti, A.; Uni, S.; Guerrero, R.; Ferte, H.; Bandi, C.; Martin, C.; Casiraghi, M. Integrated taxonomy: Traditional approach and DNA barcoding for the identification of filarioid worms and related parasites (Nematoda). Front. Zool. 2009, 6, 1. [CrossRef]

23. Verocai, G.G.; Nelson, K.J.; Callahan, R.T.; Wekesa, J.W.; Hassan, H.K.; Hoberg, E.P. A cryptic species of Onchocerca (Nematoda: Onchocercidae) in blackflies (Simulium spp.) from southern California, USA. Parasites Vectors 2018, 11, 547. [CrossRef] [PubMed]

24. Low, V.L.; Srisuka, W.; Saeung, A.; Tan, T.K.; Ya'cob, Z.; Yeong, Y.S.; Takaoka, H. DNA Barcoding of Simulium asakoae (Diptera: Simuliidae) From Northern Thailand. [published online ahead of print]. J. Med. Entomol. 2020. [CrossRef] [PubMed]

25. Jomkumsing, P.; Tangkawanit, U.; Wongpakam, K.; Pramual, P. Who is biting you? DNA barcodes reveal cryptic diversity in human-biting black flies (Diptera: Simuliidae). Acta Trop. 2019, 196, 22-29. [CrossRef] [PubMed]

26. Low, V.L.; Sofian-Azirun, M.; Norma-Rashid, Y. Playing hide-and-seek with the tiny dragonfly: DNA barcoding discriminates multiple lineages of Nannophya pygmaea in Asia. J. Insect Conserv. 2016, 20, 339-343. [CrossRef]

27. Takaoka, H.; Srisuka, W.; Low, V.L.; Maleewong, W.; Saeung, A. Two new species of Simulium (Gomphostilbia) (Diptera: Simuliidae) from Myanmar, and their phylogenetic relationships with related species in the S. asakoae species-group. Acta Trop. 2017, 176, 39-50. [CrossRef]

28. Pramual, P.; Simwisat, K.; Martin, J. Identification and reassessment of the specific status of some tropical freshwater midges (Diptera: Chironomidae) using DNA barcode data. Zootaxa 2016, 4072, 39-60. [CrossRef]

29. Pace, N.R.; Olsen, G.J.; Woese, C.R. Ribosomal RNA phylogeny and the primary lines of evolutionary descent. Cell 1986, 45, 325-326. [CrossRef]

30. Wang, J.; Xu, F.; Liu, X.; Wang, G. Molecular phylogeny of entomopathogenic nematodes (Mermithidae) inferred from DNA sequences of $18 \mathrm{~S}$ rDNA, $28 \mathrm{~S}$ rDNA and COI genes. Acta Zool. Sin. 2007, 53, 835-844.

31. Jitklang, S.; Ahantarig, A.; Kuvangkadilok, C.; Baimai, V.; Adler, P.H. Parasites of larval black flies (Diptera: Simuliidae) in Thailand. Songklanakarin J. Sci. Technol. 2012, 34, 597-599.

32. Digiani, M.C.; Sutton, C.A. New reports and a redescription of Porrocaecum heteropterum (Diesing, 1851) (Ascarididae), a rare nematode parasitic in South American.threskiornithid birds1. Syst. Parasitol. 2001, 49, 1-6. [CrossRef]

33. Crainey, J.L.; Wilson, M.D.; Post, R.J. An 18S ribosomal DNA barcode for the study of Isomermis lairdi, a parasite of the blackfly Simulium damnosum s.l. Med. Vet. Entomol. 2009, 23, 238-244. [CrossRef] [PubMed]

34. Takaoka, H.; Srisuka, W.; Saeung, A. Checklist and keys for the black flies (Diptera: Simuliidae) of Thailand. Med. Entomol. Zool. 2019, 70, 53-77. [CrossRef] 
35. Folmer, O.; Black, M.; Hoeh, W.; Lutz, R.; Vrijenhoek, R. DNA primers for amplification of mitochondrial cytochrome c oxidase subunit I from diverse metazoan invertebrates. Mol. Mar. Biol. Biotechnol. 1994, 3, 294-299. [PubMed]

36. Conflitti, I.M.; Shields, G.F.; Currie, D.C. A “complex" problem: Delimiting sibling species boundaries in black flies (Diptera: Simuliidae). Can. Entomol. 2012, 144, 323-336. [CrossRef]

37. Kumar, S.; Stecher, G.; Tamura, K. MEGA7: Molecular Evolutionary Genetics Analysis Version 7.0 for Bigger Datasets. Mol. Biol. Evol. 2016, 33, 1870-1874. [CrossRef]

38. Thompson, J.D.; Higgins, D.G.; Gibson, T.J. CLUSTAL W: Improving the sensitivity of progressive multiple sequence alignment through sequence weighting, position-specific gap penalties and weight matrix choice. Nucleic Acids Res. 1994, 22, 4673-4680. [CrossRef]

39. Darriba, D.; Taboada, G.L.; Doallo, R.; Posada, D. jModelTest 2: More models, new heuristics and parallel computing. Nat. Methods 2012, 9, 772. [CrossRef]

40. Guindon, S.; Dufayard, J.F.; Lefort, V.; Anisimova, M.; Hordijk, W.; Gascuel, O. New algorithms and methods to estimate maximum-likelihood phylogenies: Assessing the performance of PhyML 3.0. Syst. Biol. 2010, 59, 307-321. [CrossRef]

41. Ronquist, F.; Teslenko, M.; van der Mark, P.; Ayres, D.L.; Darling, A.; Hohna, S.; Larget, B.; Liu, L.; Suchard, M.A.; Huelsenbeck, J.P. MrBayes 3.2: Efficient Bayesian phylogenetic inference and model choice across a large model space. Syst. Biol. 2012, 61, 539-542. [CrossRef]

42. Kimura, M. A simple method for estimating evolutionary rates of base substitutions through comparative studies of nucleotide sequences. J. Mol. Evol. 1980, 16, 111-120. [CrossRef]

43. Zhou, S.; Fu, X.; Pei, P.; Kucka, M.; Liu, J.; Tang, L.; Zhan, T.; He, S.; Chan, Y.F.; Rodelsperger, C.; et al. Characterization of a non-sexual population of Strongyloides stercoralis with hybrid 18S rDNA haplotypes in Guangxi, Southern China. PLoS Negl. Trop. Dis. 2019, 13, e0007396. [CrossRef] [PubMed]

44. Casiraghi, M.; Anderson, T.J.; Bandi, C.; Bazzocchi, C.; Genchi, C. A phylogenetic analysis of filarial nematodes: Comparison with the phylogeny of Wolbachia endosymbionts. Parasitology 2001, 122, $93-103$. [CrossRef] [PubMed]

45. Casiraghi, M.; Bain, O.; Guerrero, R.; Martin, C.; Pocacqua, V.; Gardner, S.L.; Franceschi, A.; Bandi, C. Mapping the presence of Wolbachia pipientis on the phylogeny of filarial nematodes: Evidence for symbiont loss during evolution. Int. J. Parasitol. 2004, 34, 191-203. [CrossRef] [PubMed] 